\title{
CLOSER TO A TRUE VALUE FOR HEAVY METAL CONCENTRATIONS IN RECENT ANTARCTIC SNOW BY IMPROVED CONTAMINATION CONTROL
}

\author{
by \\ E.W. Wolff and D.A. Peel \\ (British Antarctic Survey, Natural Environment Research Council, High Cross, Madingley Road, \\ Cambridge CB3 OET, England)
}

\begin{abstract}
Recent snow from two sites in the Antarctic Peninsula has been analyzed for $\mathrm{Al}, \mathrm{Cd}, \mathrm{Cu}, \mathrm{Pb}$ and $\mathrm{Zn}$. Measurement of full procedural blanks and of the extent of penetration of surface contamination has allowed a rigorous appraisal of both sampling and analytical methods. Whilst the particular samples of cored firn used here have been shown to be unsuitable due to penetration of surface contamination into their interiors, surface samples collected directly into acrylic tubes showed very limited penetration of contamination. The surface samples gave the following average concentrations: Al: $0.7 \pm 0.3 \mathrm{ng} \mathrm{g}^{-1}, \mathrm{Cd}: 0.26 \pm 0.09 \mathrm{pg}$ $\mathrm{g}^{-1}, \mathrm{Cu}: 1.9 \pm 0.5 \mathrm{pg} \mathrm{g}^{-1}, \mathrm{~Pb}: 6.3 \pm 3.3 \mathrm{pg} \mathrm{g}^{-1}$ and $\mathrm{Zn}: 3.3 \pm 1.7$ $\mathrm{pg} \mathrm{g}^{-1}$. The $\mathrm{Pb}$ concentration agrees well with data from other workers for recent snow from East Antarctica, while the values for $\mathrm{Cd}, \mathrm{Cu}$ and $\mathrm{Zn}$ are about ten times lower than have been reported previously, even for ancient Antarctic ice. Although these data refer to only one site and a short time period, it is believed that they are representative of modern Antarctic snow.

The true concentrations of $\mathrm{Cd}, \mathrm{Cu}, \mathrm{Pb}$ and $\mathrm{Zn}$ in ancient Antarctic ice are not yet established. However the following limits are suggested for increases over natural background levels due to anthropogenic emissions: $\mathrm{Pb} 1$ to 40 times, $\mathrm{Cd} 1$ to 180 times, $\mathrm{Cu} 1$ to 4.5 times and $\mathrm{Zn} 1$ to 6 times. These results indicate that contamination may have been responsible for reports of anomalous enrichment of several heavy metals in Antarctic snow.
\end{abstract}

\section{INTRODUCTION}

For fifteen years there has been great interest in establishing heavy metal concentrations in both recent and ancient snow from the polar regions. Whilst concentrations in ancient ice establish natural background conditions in the pre-industrial atmosphere, more recent trends should reflect the extent of global pollution.

The painstaking analyses by Murozumi and others (1969) and $\mathrm{Ng}$ and Patterson (1981) have shown that lead concentrations in recent Greenland snow $\left(\sim 200 \mathrm{pg} \mathrm{g}^{-1}\right)$ are at least 100 times greater than in snow that fell thousands of years ago.

By contrast, in East Antarctica, Boutron and Patterson (1983) have reported concentrations for $\mathrm{Pb}$ of about $5 \mathrm{pg}$ $\mathrm{g}^{-1}$ in recent snow, and an upper limit of 1 to $3 \mathrm{pg} \mathrm{g}^{-1}$ in snow from previous centuries. It is not clear if these differences are due to anthropogenic emissions or to variations in as-yet-unidentified natural sources. This work showed that previously reported concentrations of lead in Antarctic snow (Boutron and Lorius 1979, Boutron 1980, 1982) were anomalously high. As a result, data for other heavy metals published in the same reports are probably suspect (Wolff and Peel 1985).

Several problems have made difficult the evaluation of the reliability of reported data. (i) Many of the data are not supported by adequate details on the extent of contamination at each stage of the analysis. A full analysis of procedural blanks, as exemplified by Boutron and Patterson (1983), must be considered an essential part of the data. (ii) It is now recognised that most conventional field-sampling techniques (including core-drilling) inevitably contaminate the sample surfaces. Even rigorous pre-cleaning of ice-coring devices has not overcome the problem (Boutron and Patterson 1983). It is therefore important to determine concentration profiles from the outside to the centre of representative samples and show directly how far external contamination has penetrated towards the interior (Boutron and Patterson 1983). In earlier work where sub-samples were taken from the centre of a sample (Landy and Peel 1981, Peel and Wolff 1982), no profiles were determined, so it was not possible to confirm whether contamination had reached the sub-sampled regions or not. Clearly, prerequisites for profiling studies include the ability to analyze relatively small samples and a technique for clean sub-sampling. (iii) Analyses which do not involve an acid digestion step must show the extent to which they are quantitative. (iv) The sample collection sites may not be representative of large areas of the Antarctic continent. For instance, snow accumulation rate, proximity to exposed rock or the ocean, and local weather patterns may all influence the deposition rate of trace elements onto the snow surface. If there are seasonal variations (such as those reported by Mart (1983) for snow from the Arctic Ocean), then samples which do not integrate entire years may be unrepresentative (Langway and others 1977).

In the present work we have analyzed recent snow samples from the Antarctic Peninsula for $\mathrm{Cd}, \mathrm{Cu}, \mathrm{Pb}$ and $\mathrm{Zn}$ using atomic absorption spectrometry after pre-concentration on tungsten wires. The technique requires minimal sample pre-treatment before analysis and is capable of analyzing small samples ( $<2 \mathrm{~g}$ for a single element). We have compared the effectiveness of various field-sampling techniques. Particular care has been taken to establish the level of contamination at each stage of the sub-sampling and analysis procedures. In some cases this has been used to improve such procedures. Concentration profiles from the outside to the centre of representative samples have been measured to establish how much surface contamination penetrates the region sub-sampled. Finally, we present a new set of data for surface snow from the Antarctic Peninsula. We discuss how representative these data are, and what implications they have for future attempts to measure heavy metal concentrations in remote areas of the world.

2. SAMPLE COLLECTION AND ANALYSIS PROCEDURES

2.1. Sample collection

Samples used in this study were collected from two areas in the southern part of the Antarctic Peninsula (Fig.1). Both areas are remote from any human activities and, apart from the isolated nunataks shown in Figure 1, remote from exposed rock.

At the site on Spaatz Island (lat $72^{\circ} 53^{\prime} \mathrm{S}$, long $74^{\circ} 41 \cdot \mathrm{W}$, altitude $408 \mathrm{~m}$ a.s.l., distance to sea $15 \mathrm{~km}$, 


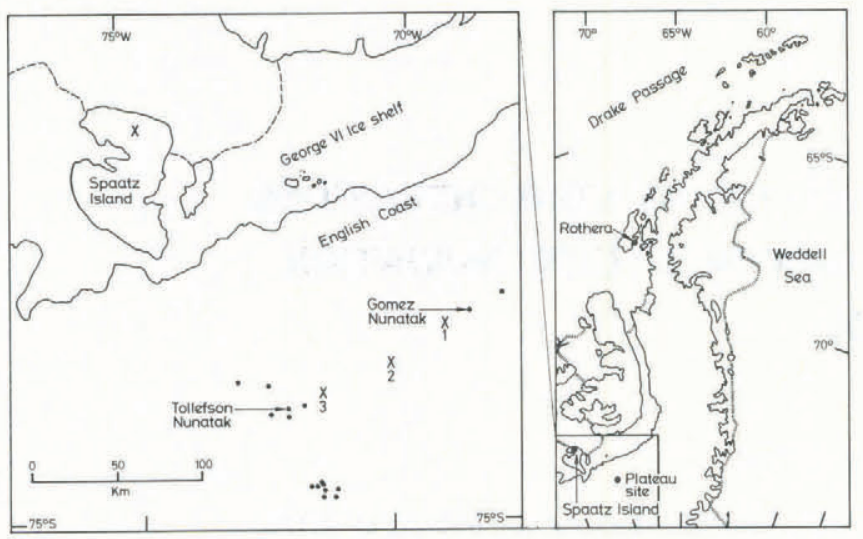

Fig.1. Sampling sites (marked as crosses) on Spaatz Island and on the southern Palmer plateau. The dots are nunataks and mountains.

accumulation $1.15 \mathrm{~m}$ water $\mathrm{a}^{-1}, 10 \mathrm{~m}$ temperature $-12.5^{\circ} \mathrm{C}$ ), cores were drilled in January 1980 with an aluminium hand-drill of $10 \mathrm{~cm}$ diameter. Although the field party was airlifted to the site, contamination from this source probably affected the surface of the snow cover only. No surface vehicles were used. The drill site was about $100 \mathrm{~m}$ upwind of the camp site. The only previous recorded visit to Spaatz Island had been some $10 \mathrm{~km}$ west from the present site in 1975.

The drill was partially cleaned by drilling several pilot holes immediately before drilling the sample core. The operators wore full clean-room clothing whilst drilling. The tubes along with other field-sampling equipment had been roughly pre-cleaned by a procedure which, by current standards, is rather primitive and is likely to have left elevated metal concentrations on the inner surfaces. The procedure involved two overnight soaks in analytical grade $10 \% \mathrm{HNO}_{3}$, one soak in analytical grade $10 \% \mathrm{HCl}$ and one in "purest water". The tubes were transported to the field sealed in polyethylene bags.

In the region near Gomez Nunatak (lat $74^{\circ} \mathrm{S}$, long $70^{\circ} \mathrm{W}$, distance from sea $150 \mathrm{~km}$, altitude $\sim 1100 \mathrm{~m}$ a.s.1.), near-surface samples were collected during February 1980 in acrylic tubes of $10 \mathrm{~cm}$ diameter (cleaned as described in the last paragraph) at three sites, as shown in Figure 1. The accumulation rate at a nearby site is $0.88 \mathrm{~m}$ water $\mathrm{a}^{-1}$, and the $10 \mathrm{~m}$ temperature is $-17.3^{\circ} \mathrm{C}$. At each of the three sites, one operator, dressed in full clean-room clothing, walked $30 \mathrm{~m}$ upwind of the vehicles. Using a spade, he dug a small area to remove the uppermost soft layer of snowfall (about $20 \mathrm{~cm}$ thick). He then scraped away a further $3 \mathrm{~cm}$ with a pre-cleaned PTFE scraper. Samples were collected by pushing the containers upwind and away from the operator along the fresh surface. This procedure ensured that contamination from the approach of the vehicle was not included, and that samples of the same snowfalls (which had probably fallen at the end of January 1980) were collected at each site. Three acrylic tubes (64 cm long) were filled at each of the three sites. Each sample probably integrated about $10 \mathrm{~cm}$ snowfall. This represents the snowfall occurring between one day and, at most, a few weeks at these sites.

The tubes collected at all sites were sealed in polyethylene bags and buried to $1 \mathrm{~m}$ minimum snow depth in insulated boxes; temperatures at this depth were about $-5^{\circ} \mathrm{C}$ at Spaatz Island and $-10^{\circ} \mathrm{C}$ near Gomez Nunatak. They were subsequently carried in the unheated cabin of a Twin Otter aircraft to freezers at $-20^{\circ} \mathrm{C}$ on Rothera base. They were returned in a ship's deep freeze at $-10^{\circ} \mathrm{C}$ to England, where they were stored at $-20^{\circ} \mathrm{C}$ before analysis. It is probable that the greatest risk of contamination penetrating the cores will have occurred when they were warmest, i.e. on the ship and during storage in the field (approximately two weeks at both sites).

\subsection{Laboratory conditions}

Sub-sampling procedures took place inside a laminar-flow clean-air bench inside a cold room at $-20^{\circ} \mathrm{C}$.
All other work was carried out in a class 100 clean room or in a laminar-flow clean-air bench. The atomic absorption spectrometer was situated in a conventional laboratory. However, a piped clean-air supply was passed obliquely over the graphite rod, to prevent particle deposition without blocking the flow of oxygen-free $\mathrm{N}_{2}$ over the rod. Full clean-room clothing, including an eye-slit hood, was worn throughout. "Purest water" was obtained by passing tap water through a pre-deionizer and a double glass still. The still output was pumped to a recirculating Millipore "Milli-Q" deionization system. The output water typically contained the following concentrations of heavy metals: 0.05 $\mathrm{pg} \mathrm{g}^{-1} \mathrm{Cd}, 0.4 \mathrm{pg} \mathrm{g}^{-1} \mathrm{Cu}, 1.5 \mathrm{pg} \mathrm{g}^{-1} \mathrm{~Pb}$ and $1 \mathrm{pg} \mathrm{g}^{-1}$ $\mathrm{Zn}$.

Items used for sub-sampling and pre-concentration, including sub-corers, hooks, outer containers, and gloves, were cleaned by the following soaks at room temperature in polyethylene acid baths which had themselves been pre-cleaned previously: (i) rinse in detergent, hot and cold tap water, and "purest water", (ii) $12 \mathrm{~h}$ in $10 \% \mathrm{HNO}_{3}+10 \%$ $\mathrm{HCl}$ (both analytical grade), (iii) $12 \mathrm{~h}$ in $20 \% \quad \mathrm{HNO}_{3}$ (analytical grade); (iv) $12 \mathrm{~h}$ in $1 \mathrm{M} \mathrm{HNO}_{3}$ ("Aristar"), (v) items transferred to class 100 clean room in bath containing pH 3 "Aristar" $\mathrm{HNO}_{3}$, (vi) $>12 \mathrm{~h}$ in pH 2 "Aristar" $\mathrm{HNO}_{3}$, (vii) $>12 \mathrm{~h}$ in $\mathrm{pH} 3$ "Aristar" $\mathrm{HNO}_{3}$. "Aristar" $\mathrm{HNO}_{3}(70 \%$ $\mathrm{HNO}_{3}$ ) has the following maximum levels of impurities: 5 $\mathrm{ng} \mathrm{g^{-1 }} \mathrm{Cd}, 5 \mathrm{ng} \mathrm{g}^{-1} \mathrm{Cu}, 2 \mathrm{ng} \mathrm{g}^{-1} \mathrm{~Pb}$ and $10 \mathrm{ng} \mathrm{g}^{-1} \mathrm{Zn}$. The acids were diluted using "purest water".

\subsection{Sample preparation}

It was assumed that samples would be contaminated on all exposed ends (e.g. breaks in the core). Initially, a fresh sample face was prepared by sliding the core into an acrylic cutting jig, and splitting it with a pre-cleaned PTFE slicer. This slicer, illustrated schematically in Figure 2, left the central areas of the core (to be sub-cored) totally

Polyethylene strengthening

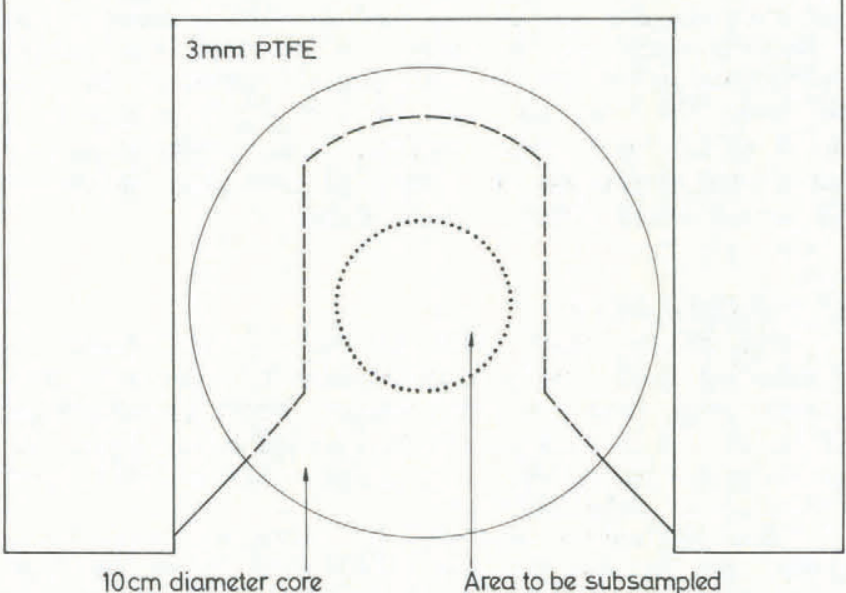

Fig.2. The arched slicer used for splitting ice cores. The central section of the core, which is later sub-cored, is untouched.

untouched. Later, it was found possible to produce totally untouched surfaces by splitting the core as it straddled two acrylic tubes. The latter method, which eliminates any possibility of external contamination being swept towards the centre, was used for all the surface samples and some cores.

Sub-sampling was routinely carried out using a PTFE cylinder (38 mm inside diameter, $43 \mathrm{~mm}$ outside diameter $\mathrm{x}$ $68 \mathrm{~mm}$ deep) which also served as the analysis vessel. It was pre-cleaned by the normal procedure and left filled with "purest water" acidified to $\mathrm{pH} 3$ until required. This 
sub-corer was placed, open end down, on the freshly prepared face of the sample and forced into the core using a pre-cleaned polyethylene mallet. It was then removed and mounted (open end up) on the lid of a pre-cleaned polythene bottle of 21 capacity. The bottle was screwed onto the lid to protect the sub-corer while it was transported to clean areas at $\sim 20^{\circ} \mathrm{C}$ for melting and preconcentration. The sub-corer was touched only with pre-cleaned gloves.

A small sub-corer, similar in design, but only $8 \mathrm{~mm}$ inside diameter and $13 \mathrm{~mm}$ outside diameter, was used to profile single elements across selected cores. In this case, a series of sub-samples was taken at varying distances from the centre of the sample. The sample was covered (in the cold-room clean-air bench) between successive sub-sample collections.

In both cases, the covered corer was weighed (sub-samples were in the range from 25 to $30 \mathrm{~g}$ for the large sub-corer, and from 1 to $2 \mathrm{~g}$ for the small sub-corer), and then placed in a microwave oven to melt the sample, which took from 1 to $3 \mathrm{~min}$.

All samples were acidified to $\mathrm{pH} 3$ ("Aristar" $\mathrm{HNO}_{3}$ ) using pre-cleaned polyethylene pipette tips. A PTFE magnetic stir bar was added to the larger sub-corer. The sample in the small sub-corer was not stirred. The stirrer bar was stored on a PTFE grid, so that it could be easily cleaned. This also enabled the sub-corer to be emptied through the grid with no risk of dropping the stir bar.

\subsection{Analysis}

For all $\mathrm{Al}$ and $\mathrm{Zn}$ analyses, and for measuring elevated surface concentrations of $\mathrm{Cd}, \mathrm{Cu}$ and $\mathrm{Pb}$, analysis was by multiple direct injections into a flameless (graphite boat) atomic absorption spectrometer (Baird Atomic A 5100 with A 3470 flameless atomiser). Pre-cleaned polyethylene pipette tips were used to inject $50 \mu 1$ aliquots of sample. Generally, three injections for $\mathrm{Zn}$ and ten injections for $\mathrm{Al}$ were sufficient for each analysis. $10 \% \mathrm{Ar} / \mathrm{CH}_{4}$ at $200 \mathrm{ml}$ $\mathrm{min}^{-1}$ was added to a $\mathrm{N}_{2}$ gas flow of $2.51 \mathrm{~min}^{-1}$ for $\mathrm{Al}$ analysis. The detection limit for the method itself (ignoring procedural blanks) is given in Table I. This value can be lowered virtually pro rata by performing more injections (up to 20).

After samples for injection had been removed, $\mathrm{Cd}, \mathrm{Cu}$ and $\mathrm{Pb}$ were analyzed (in the large sub-corer) by direct preconcentration onto tungsten wire loops (Wolff and others 1981). These loops were analyzed in the graphite boat of the atomic absorption spectrometer. Eight tungsten wire loops were suspended on pre-cleaned FEP hooks, and lowered into the stirred solution at room temperature, generally for $60 \mathrm{~min}$. Each wire was $34 \mathrm{~mm}$ long (unbent) $x 0.5 \mathrm{~mm}$ diameter and weighed $0.1305 \pm 0.003 \mathrm{~g}$. The cover on which the hooks and wires were mounted was never allowed to touch the rim of the sub-corer. The wires were transferred to and from the graphite boat with pre-cleaned stainless steel tweezers whose tips were covered in fine FEP tubing.

Calibrations were produced by adding mixed standards, both to "purest water" and to sample solutions. No difference was found between the two procedures, indicating that this simple sample matrix does not affect the sensitivity. A calibration for $\mathrm{Cu}\left(0\right.$ to $\left.10 \mathrm{pg} \mathrm{g}^{-1}\right)$ is shown in Figure 3. The detection limit for the method itself (ignoring procedural blanks) is given in Table I. It would be possible to improve the sensitivity by both performing longer runs and using fewer wires per run (a limiting factor is that eight wires equilibrated for $1 \mathrm{~h}$ may remove more than $50 \%$ of some metals from solution).

Tungsten wire runs were also carried out in profiling experiments for $\mathrm{Pb}$ using the small sub-sampler. In this

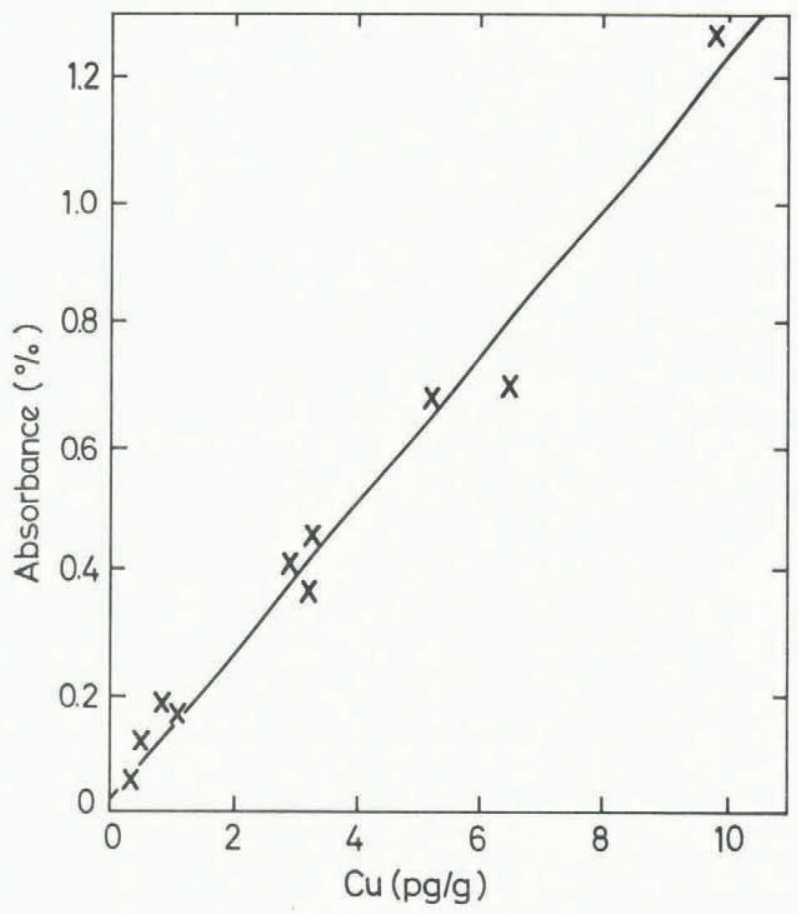

Fig.3. A calibration curve for $\mathrm{Cu}$ using eight tungsten wires immersed for $1 \mathrm{~h}$, followed by analysis by flameless atomic absorption spectrometry.

TABLE I. SENSITIVITIES AND DETECTION LIMITS OF THE ANALYTICAL METHODS

\begin{tabular}{|c|c|c|c|c|c|c|}
\hline Element & Method & $\stackrel{\lambda}{\lambda(\mathrm{nm})}$ & $\begin{array}{l}\text { Calibration } \\
\text { range } \\
\left(\mathrm{pg} \mathrm{g}^{-1}\right)\end{array}$ & $\begin{array}{l}\text { Scale } \\
\text { expansion } \\
\text { used }\end{array}$ & $\begin{array}{l}\text { Sensitivity* } \\
\left(\mathrm{pg} \mathrm{g}^{-1}\right)\end{array}$ & $\begin{array}{l}\text { Detection limit** } \\
\quad\left(\mathrm{pg} \mathrm{g}^{-1}\right)\end{array}$ \\
\hline Al & $\begin{array}{l}\text { Direct injections } \\
10 \text { injections }\end{array}$ & 309.2 & $500-5000$ & $10 x$ & 2200 & $400^{* * *}$ \\
\hline $\mathrm{Cd}$ & $\begin{array}{l}\text { W wire } \\
60 \text { min }\end{array}$ & 228.1 & $0.1-1$ & $10 x$ & 0.6 & 0.10 \\
\hline $\mathrm{Cu}$ & $\begin{array}{l}\text { W wire } \\
60 \mathrm{~min}\end{array}$ & 324.7 & $1-10$ & $10 x$ & 3.4 & 0.8 \\
\hline $\mathrm{Pb}$ & $\begin{array}{l}\text { W wire } \\
60 \mathrm{~min}\end{array}$ & 283.3 & $1-10$ & $10 x$ & 10.5 & 2.0 \\
\hline $\mathrm{Zn}$ & $\begin{array}{l}\text { Direct injections } \\
3 \text { injections }\end{array}$ & 213.9 & $1-10$ & $5 x$ & 2.8 & $1.5^{* * *}$ \\
\hline
\end{tabular}

* Sensitivity defined as concentration for $1 \%$ absorption $(0.435 \%$ absorbance) as determined from regression lines of calibrations.

** Detection limit defined as concentration giving a signal equal to twice the RMS noise.

*** Detection limit can be lowered by using more injections. 
case, the sub-sampler was agitated by immersing it in "purest water" in a container held in an ultrasonic bath. One wire only was equilibrated for $1 \mathrm{~h}$. Due to the smaller sample volume and less efficient stirring, the detection limit was about $5 \mathrm{pg} \mathrm{g}^{-1}$.

\subsection{Procedural blanks}

Contamination will be added at every stage of a sampling and analysis procedure. Whatever is added to the outside of a sample during collection, storage and transport may penetrate towards the centre, especially in open-textured firn. The profiling experiments, described separately, are designed to establish the extent both of the exterior contamination, and the penetration towards the centre.

After the samples have been opened in the home laboratory, contamination can be introduced from a number of sources (Table II). Blanks obtained at each stage for the large sub-corer are shown in Table II. Slightly larger and more variable blanks were obtained for the small sub-corer due to both the inherent difficulty of cleaning a vessel of such a small diameter and the larger surface area/sample volume ratio. Measurements such as those in Table II allowed improvement of some stages of the analytical method, for example leading to the use of FEP hooks instead of platinum hooks which were employed at first.

The blank for the beaker and stir bar, separated from that of "purest water" (which is not used in the actual analysis), is the most difficult to obtain. The procedure used here, which takes advantage of the stripping pre-concentration procedure, eliminates the influence of the water blank. When tungsten wires are left in solution for many hours, the solution becomes severely depleted in heavy metal ions. These can be replenished only by leaching from the sub-sampler and stir bar surfaces. In practice, after a series of equilibrations, the heavy metal concentration in solution could be reduced to a steady, very low value. Provided an authentic sample is added to a sub-corer which has been cleaned to this point, then the "steady state" concentration can be treated as the container blank.

Between three and five equilibrations were made, each lasting several hours, between each of which the eight tungsten wires were cleaned by flash-heating in the graphite rod. This was followed by a normal run for $1 \mathrm{~h}$ using eight wires. In this way the water and acid blank were eliminated, leaving the contribution from continuous leaching of the sub-corer, stir bar and hooks, and from the tweezers, tungsten wires, graphite rod and air. All but the first two of these contributions were evaluated independently, so that the beaker/stir bar blank, which is

TABLE II. CONTRIBUTION OF PROCEDURAL STAGES TO BLANK FOR LARGE SUBCORER (60 min runs or direct injections)

\begin{tabular}{|c|c|c|c|c|c|c|}
\hline \multirow[b]{2}{*}{ Stage of procedure } & \multirow[b]{2}{*}{ Method of determining blank } & \multicolumn{5}{|c|}{ Blank contribution $\left(\mathrm{pg} \mathrm{g}^{-1}\right)$} \\
\hline & & Al & $\mathrm{Cd}$ & $\mathrm{Cu}$ & $\mathrm{Pb}$ & $\mathrm{Zn}$ \\
\hline Slicer (if used) & $\begin{array}{l}\text { Does not contact final sub-sample, therefore } \\
\text { assumed zero. }\end{array}$ & 0 & 0 & 0 & 0 & 0 \\
\hline $\begin{array}{l}\text { Sub-sampling } \\
\text { (abrasion of } \\
\text { sub-sampler) }\end{array}$ & $\begin{array}{l}\text { Measure weight loss of PTFE from sub-sampler after } \\
10 \text { sub-samplings. Assume, as worst case, total metal } \\
\text { content of lost PTFE is dissolved in sample. Metal } \\
\text { content of PTFE estimated from Moody and Lindstrom } \\
\text { (1977) and J R Moody (personal communication). }\end{array}$ & 5 & $<0.1$ & $<0.2$ & $<0.1$ & $<0.5$ \\
\hline $\begin{array}{l}\text { Airborne } \\
\text { contamination }\end{array}$ & $\begin{array}{l}\text { Increase in concentration of pure water left for } 24 \mathrm{~h} \text {, } \\
\text { covered and uncovered. }\end{array}$ & $<10$ & $<0.002$ & $<0.1$ & $<0.2$ & $<0.02$ \\
\hline Acid at $\mathrm{pH} 3$ & $\begin{array}{l}\text { Direct injections of acid into graphite rod, with } \\
\text { standard addition calibrations. }\end{array}$ & $<5$ & 0.03 & 0.03 & 0.08 & 0.25 \\
\hline $\begin{array}{l}\text { Pipette tip for } \mathrm{Zn} \\
\text { and Al analysis } \\
\text { (direct injection } \\
\text { only) }\end{array}$ & $\begin{array}{l}\text { Sucked up } 100 \times 50 \mu \mathrm{l} \text { aliquots from } 1 \mathrm{ml} \text { of } \\
\text { "purest water", and returned aliquots to beaker. } \\
\text { Measured concentration increase. }\end{array}$ & $<150$ & - & - & - & $<0.4$ \\
\hline $\begin{array}{l}\text { Pipette tips (as } \\
\text { used above). } \\
\text { Effect on } \mathrm{Cd}, \mathrm{Cu} \text {, } \\
\mathrm{Pb} \text { (W wire } \\
\text { analysis) }\end{array}$ & $\begin{array}{l}\text { Dipped pipette tip in sample } 100 \mathrm{x} \text { and measured } \\
\text { concentration increase. }\end{array}$ & - & $<0.05$ & $<0.08$ & $<0.2$ & - \\
\hline FEP hooks & $\begin{array}{l}\text { Up to five FEP hooks left in stirred solution to } \\
\text { obtain their contribution. }\end{array}$ & - & $<0.05$ & $<0.5$ & $<0.5$ & - \\
\hline Tweezers & Handled wire 20 times with tweezers. & - & 0.02 & 0.1 & 0.1 & - \\
\hline Rod and wire & $\begin{array}{l}\text { Upper limits from dry blanks against noise level, } \\
\text { evaluated statistically over many runs. }\end{array}$ & $<100$ & $<0.05$ & $<0.04$ & $<0.2$ & $<0.01$ \\
\hline $\begin{array}{l}\text { Sub-sampler and } \\
\text { stir bar (wet) }\end{array}$ & See text. & $<150$ & $<0.1$ & $<0.7$ & 3.0 & 2.2 \\
\hline Total & & $<150$ & $<0.13$ & $<1$ & 3.3 & 2.5 \\
\hline $\begin{array}{l}\text { Blank subtracted } \\
\text { from each } \\
\text { sample run }\end{array}$ & & 75 & 0.07 & 0.5 & 3.3 & 2.5 \\
\hline Standard deviation & $\begin{array}{l}\text { Approximated - due to variations in blank dependent } \\
\text { on previous conditions. }\end{array}$ & 75 & 0.07 & 0.5 & 2 & 1 \\
\hline
\end{tabular}


the largest component of the blank, could be evaluated separately. The water blank was determined by adding a sample of "purest water" to a stripped sub-coring vessel and conducting a normal run of $1 \mathrm{~h}$. The sub-coring vessels were stripped routinely to the blank levels reported in Table II before sub-coring and analysis of each authentic sample. It was, however, possible on occasions to reduce this blank for $\mathrm{Pb}$ and $\mathrm{Zn}$ to around $1 \mathrm{pg} \mathrm{g}^{-1}$ each. Procedural blanks given in Table II were subtracted from each sample value.

The blanks estimated above are only procedural blanks. There will also, as we have stated, be an internal sample blank due to contamination introduced during the collection and storage of the solid core. In many cases, this could be dominant, as exemplified by earlier reports (Boutron and Lorius 1979, Boutron 1980, 1982) where the precision of the whole analytical procedure was estimated to be in the range from 10 to $100 \%$. However, it was subsequently shown (Boutron and Patterson 1983) that the values given were a factor of four or more too high due to sample contamination.

\section{RESULTS}

\subsection{Profiling experiments}

The large sub-sampling tool cuts a cylindrical core of $3.7 \mathrm{~cm}$ diameter from samples which may be $10 \mathrm{~cm}$ in diameter. It is therefore essential to test whether contamination has penetrated to this depth below the surface. A small sub-sampler is used to extract several plugs at different distances across a sample. The methods used here are able to analyze samples as small as 1 or $2 \mathrm{~g}$ with sufficient sensitivity for these experiments. In general it is suspected that elevated concentrations will occur on the outer surface, and that these will reduce towards the centre. Only if they fall to a constant value outside the sub-sampling zone can it be assumed that the central concentration is representative of uncontaminated snow. Although the main purpose of these experiments was to determine if a satisfactory plateau was reached, it was also hoped to identify the major causes of surface contamination. As the experiments are very time-consuming, full profiles were performed only for some elements (usually $\mathrm{Zn})$. The surface concentrations of the other elements were then measured and interior values estimated, assuming that they decayed towards the centre at the same rate.

\subsubsection{Spaatz Island}

Profiles were determined for several samples from a core drilled to $15 \mathrm{~m}$ depth with an aluminium drill at this site. Profiles for $\mathrm{Pb}, \mathrm{Zn}$ and $\mathrm{Al}$ are shown in Figure 4. High exterior values are found for all the elements, but contamination reached the centre in significant amounts for $\mathrm{Zn}$ only. The central $\mathrm{Zn}$ concentration for these profiles is on average around $2 \%$ of the exterior concentration.
Assuming initially that this is entirely due to contamination, we estimate an upper limit for contamination of the other elements penetrating the centre based on the surface concentrations of these elements. These estimates for $\mathrm{Pb}(1$ $\left.\mathrm{pg} \mathrm{g}^{-1}\right)$ and A1 $\left(0.2 \mathrm{pg} \mathrm{g}^{-1}\right)$ would not be detectable, suggesting that the central values for these elements may be approximately correct.

The exterior concentrations measured for $\mathrm{Cd}$ and $\mathrm{Cu}$ varied from point to point on the surface but median values for $\mathrm{Cd}$ of $50 \mathrm{pg} \mathrm{g}^{-1}$ and for $\mathrm{Cu}$ of $500 \mathrm{pg} \mathrm{g}^{-1}$ were typical. Thus, if $\mathrm{Cd}$ and $\mathrm{Cu}$ contamination decayed in parallel with the observed $\mathrm{Zn}$ profile $\sim 1 \mathrm{pg} \mathrm{g}^{-1} \mathrm{Cd}$ and $\sim 10$ $\mathrm{pg} \mathrm{g}^{-1} \mathrm{Cu}$ contamination would have penetrated to the centre. Somewhat larger values would be obtained in a central core extending to $18.5 \mathrm{~mm}$ from the centre, which was the radius of the large sub-corer.

Large sub-samples were analyzed, from samples originating from depths between 4.26 and $5.21 \mathrm{~m}$. Five samples gave means and standard deviations of Al $1.9 \pm 0.7$ $\mathrm{pg} \mathrm{g}^{-1}, \mathrm{Cd} 0.8 \pm 0.5 \mathrm{pg} \mathrm{g}^{-1}, \mathrm{Cu} 19 \pm 2 \mathrm{pg} \mathrm{g}^{-1}, \mathrm{~Pb} 6.7 \pm 2.4 \mathrm{pg}$ $\mathrm{g}^{-1}$, $\mathrm{Zn} 82 \pm 8 \mathrm{pg} \mathrm{g}^{-1}$, while two samples gave values 2 to 5 times higher for $\mathrm{Cd}, \mathrm{Cu}$ and $\mathrm{Zn}$. With the exception of $\mathrm{Pb}$ and $\mathrm{Al}$ these concentrations are similar to the values predicted for contamination penetrating to the centre of the samples. Thus for $\mathrm{Cd}, \mathrm{Cu}$ and $\mathrm{Zn}$ the measured values appear to have been dominated by contamination. Any data for these elements from this core must therefore be considered worthless.

Attempts were made to identify the source of contamination by either soaking components of the drilling equipment or sample containers in "purest water", or by scraping them along a core of known composition. The core-catchers, which were made of brass, were the most likely source of $\mathrm{Cu}$ and $\mathrm{Zn}$. Brass can be replaced by a more suitable material, so this type of drill cannot be entirely ruled out for heavy metal work on the basis of our data. Neither the plastic bags nor the acrylic tubes produced significant contamination in these soaking experiments. Similar contamination profiles were measured on cores stored in both types of container.

Perhaps more crucially, significant penetration by diffusion could occur only at high temperatures. Although no visible signs of melting were observed in the Spaatz Island cores, the liquid-like layer on the surface of ice crystals may be significantly thick at $-5^{\circ} \mathrm{C}$ to provide a mechanism for diffusive transport of contamination. Therefore greater care to store samples at temperatures well below the freezing point is essential. This may be difficult to achieve at many field sites, even where the mean annual air temperature is as low as $-15^{\circ} \mathrm{C}$.

\subsubsection{Sites on the southern Palmer Land plateau}

Contamination profiles were measured on samples from several tubes; representative data for $\mathrm{Zn}$ and $\mathrm{Al}$ are shown
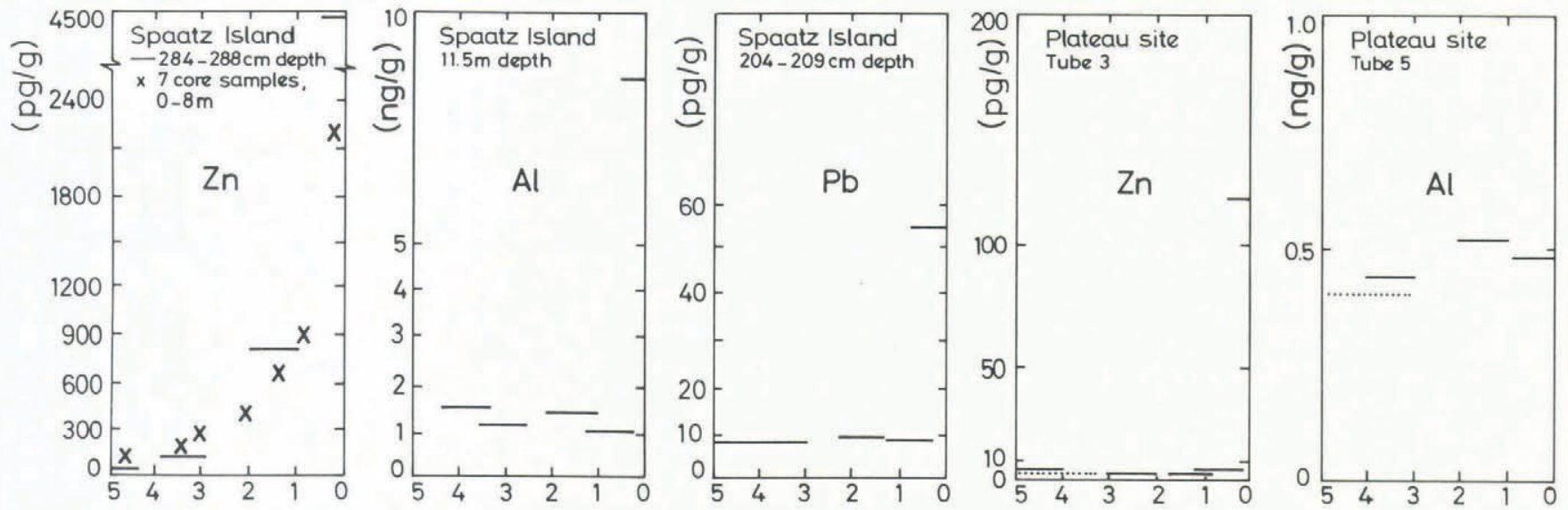

Distance from outside $(\mathrm{cm})$

Fig.4. Profiles taken across cores from Spaatz Island for $\mathrm{Zn}, \mathrm{Al}$ and $\mathrm{Pb}$, and across surface samples from the southern Palmer Land plateau for $\mathrm{Zn}$ and Al. Dotted lines show the average value obtained with the large sub-sampler. The crosses on the $\mathrm{Zn}$ profile from Spaatz Island are the composite averaged values for seven samples. 
in Figure 4. Much lower sample surface concentrations were obtained for both $\mathrm{Zn}$ and $\mathrm{Al}$ compared with concentrations in the Spaatz Island samples. The fall-off in concentration with distance from the surface is much steeper than at Spaatz Island. A plateau is clearly reached within a few $\mathrm{mm}$ of the surface. The excess concentration at about $5 \mathrm{~mm}$ depth is less than $1 \mathrm{pg} \mathrm{g}^{-1}$ for $\mathrm{Zn}$, or $1 \%$ of the surface value. Surface concentrations were also measured for sample 3 for $\mathrm{Cd}\left(<1 \mathrm{pg} \mathrm{g}^{-1}\right), \mathrm{Cu}\left(20 \mathrm{pg} \mathrm{g}^{-1}\right)$ and $\mathrm{Pb}\left(<10 \mathrm{pg} \mathrm{g}^{-1}\right)$. Applying the decay curve for $\mathrm{Zn}$ to these values the likely level of contamination for the other elements at $5 \mathrm{~mm}$ depth below the surface would be: $<0.01$ $\mathrm{pg} \mathrm{g}^{-1}$ for $\mathrm{Cd}, 0.2 \mathrm{pg} \mathrm{g}^{-1}$ for $\mathrm{Cu}$ and $<0.1 \mathrm{pg} \mathrm{g}^{-1}$ for $\mathrm{Pb}$. In the central area sampled by the large sub-sampler, contamination would be expected at a level at least an order of magnitude smaller than these values. The values measured at the centre of these surface samples are therefore probably close to the true snow concentrations.

We believe that the much cleaner profile of these surface samples compared with the Spaatz Island samples arises mainly because: (i) samples were collected directly into pre-cleaned acrylic containers, avoiding contact with any metal (this approach could be adapted to deeper sampling from snow pits), and (ii) air temperatures were lower during the collection and storage of samples in the field $\left(-10\right.$ to $\left.-15^{\circ} \mathrm{C}\right)$, which would have caused much less penetration of surface contamination.

Another contributory factor may have been that these samples were snapped rather than sliced across (as the Spaatz cores were) which may have reduced the possibility of transferring contamination from the surface to the central area of sample. It is also possible that the exterior contamination was added at a later stage to these samples, allowing less time for penetration.
3.2. Results of surface sample analyses on the southern Palmer Land plateau

3.2.1. Measured concentrations

The large sub-sampler was used to extract samples from each of the tubes of snow from these three sites. The results, corrected for procedural blanks but not for profiling contamination, are shown in Table III. One tube (no. 6 from site 3) showed signs of limited melting on the outside of the sample. It also gave consistently higher values (by a factor 10 to 50 times for $\mathrm{Zn}$ ) than the other two tubes from the same site, and has not been included in Table III. In addition, the data in brackets have been omitted from subsequent discussion. Although there is no practical justification for this, they are all more than $4 \sigma$ from the mean of the other points, and must have been inadvertently contaminated.

The standard deviations in Table III are only slightly higher than those of the procedural blanks in Table II. The differences between individual sample concentrations are not statistically meaningful. Except for Al (and Cd at site 2), the means at each of the three sites lie within the mutual $\sigma$ values. The trend in the Al data may reflect distance downwind from a nunatak (Gomez), but this conclusion must await further data. There are no statistically significant correlations between data sets for pairs of metals. This is again expected if most of the intersample variation is due to random errors of the analysis and blank.

The upper limits of contamination, which, we concluded, could have reached the centre of these samples, are much smaller than the values we have found. We therefore believe that these values, though imprecise, are not affected by contamination.

3.2.2. Enrichment factors

TABLE III. CONCENTRATIONS MEASURED ON SURFACE SAMPLES FROM SITES ON THE SOUTHERN PALMER LAND PLATEAU

\begin{tabular}{|c|c|c|c|c|c|c|}
\hline SITE & SAMPLE & Al $\left(n g g^{-1}\right)$ & $\mathrm{Cd}\left(\mathrm{pg} \mathrm{g}^{-1}\right)$ & $\mathrm{Cu}\left(\mathrm{pg} \mathrm{g^{-1 } )}\right.$ & $\mathrm{Pb}\left(\mathrm{pg} \mathrm{g^{-1 } )}\right.$ & $\mathrm{Zn}\left(\mathrm{pg} \mathrm{g}^{-1}\right)$ \\
\hline 1 & 7 & 0.85 & 2.3 & 2.3 & 4.7 & 5.2 \\
\hline 1 & 7 & 1.2 & [ 1.5$]$ & [ 5.5] & {$[20]$} & [30] \\
\hline 1 & 7 & 0.9 & [ 1.0$]$ & 1.1 & 13 & 3.6 \\
\hline 1 & 8 & 1.2 & 0.16 & 2.2 & 6.7 & 1.0 \\
\hline 1 & 9 & 1.0 & 0.17 & 2.0 & 3.1 & 7.4 \\
\hline 1 & 9 & 1.0 & 0.28 & 2.1 & [36] & 3.4 \\
\hline 2 & 1 & 0.5 & 0.34 & 2.3 & 3.3 & 3.1 \\
\hline 2 & 2 & 0.6 & 0.30 & 1.1 & 9.8 & 1.9 \\
\hline 2 & 2 & 0.7 & 0.31 & 1.4 & 9.8 & 1.0 \\
\hline 2 & 3 & 0.5 & 0.41 & 2.2 & 5.3 & 3.5 \\
\hline 3 & 4 & 0.4 & 0.22 & 1.8 & 6.0 & 2.8 \\
\hline 3 & 5 & 0.3 & 0.21 & 1.3 & 5.3 & 3.1 \\
\hline 3 & 5 & 0.5 & 0.12 & 2.5 & 2.6 & 3.5 \\
\hline \multicolumn{2}{|c|}{ All samples* } & 0.7 & 0.26 & 1.9 & 6.3 & 3.3 \\
\hline \multicolumn{2}{|c|}{ Mean $\pm \begin{array}{l}\text { standard } \\
\text { deviation }\end{array}$} & \pm 0.3 & \pm 0.09 & \pm 0.5 & \pm 3.3 & \pm 1.7 \\
\hline \multirow{2}{*}{\multicolumn{2}{|c|}{ Site 1}} & 1.0 & 0.23 & 1.9 & 6.9 & 4.1 \\
\hline & & \pm 0.2 & \pm 0.07 & \pm 0.5 & \pm 4.3 & \pm 2.4 \\
\hline \multirow{2}{*}{\multicolumn{2}{|c|}{ Site 2}} & 0.6 & 0.34 & 1.8 & 7.1 & 2.4 \\
\hline & & \pm 0.1 & \pm 0.05 & \pm 0.6 & \pm 3.3 & \pm 1.1 \\
\hline \multirow{2}{*}{\multicolumn{2}{|c|}{ Site 3}} & 0.4 & 0.18 & 1.9 & 4.6 & 3.1 \\
\hline & & \pm 0.1 & \pm 0.06 & \pm 0.6 & \pm 1.8 & \pm 0.4 \\
\hline
\end{tabular}

* except values in brackets ( $>4$ standard deviations from mean). 
Crustal enrichment factors (EF), defined as

$$
E F=\frac{[\mathrm{X}]_{\text {SNOW }} /[\mathrm{A} 1]_{\text {SNOW }}}{[\mathrm{X}]_{\text {CRUST }} /[\mathrm{A} 1]_{\text {CRUST }}}
$$

are given in Table IV. In general the trends in EFs follow (inversely) changing $\mathrm{Al}$ values. This result tends to support the hypothesis that a significant component of the metals is derived from a fairly constant, non-crustal source.

\section{DISCUSSION}

\section{1. $\underline{\text { Lead }}$}

The mean concentration of $\mathrm{Pb}$ in near-surface snowfall for a group of sites on the southern Palmer Land plateau is $6.3 \pm 3.3 \mathrm{pg} \mathrm{g}^{-1}$. This represents probably just one snowfall in late January 1980. A mean $\mathrm{Pb}$ concentration of $6.7 \pm 2.4 \mathrm{pg}$ $\mathrm{g}^{-1}$ for several months of snow (summer/autumn 1977-78) at Spaatz Island was probably not affected significantly by contamination.

These data can be compared to the results of other workers. Wolff and Peel (1985) have concluded that all but two previous studies of Antarctic lead concentrations were clearly invalidated by contamination problems. Boutron and Patterson (1983), whose data were supported by across-core profiles, found an average concentration of $4.3 \mathrm{pg} \mathrm{g}^{-1}$ in snow that fell at a coastal low-accumulation site in East Antarctica between 1949 and 1966. Bearing in mind that concentrations may have increased between 1966 and 1980, this value is entirely consistent with our data. Landy and Peel (1981) found a mean of $8.8 \mathrm{pg} \mathrm{g}^{-1}$ for snow (dated 1974-77) from a site on the Antarctic Peninsula, but their sub-samples may still have included some contamination.

Our data may not, however, be completely representative of Antarctic $\mathrm{Pb}$ concentrations.

(i) Our samples integrate short time periods only during the Antarctic summer. Marked seasonal variations have been reported in the Arctic (Mart 1983, Langway and others 1977). However the geographical isolation and zonal meteorological pattern in Antarctica are unlikely to produce an effect of similar magnitude to that observed in the Arctic.

(ii) The concentration measured in snow may depend on the accumulation rate at the sample collection site. Under the clean air conditions of Antarctica, it is probable that most heavy metals are precipitated by rainout (in-cloud nucleation) (Junge 1977). Shaw (1980) calculated that only $3 \%$ of particulate input to the Antarctic ice sheet was by dry deposition, while Davidson and others (1981) found that, in Greenland, $<25 \%$ of the input of various heavy metals was by dry deposition. It is therefore unlikely that the concentration will be strongly dependent on accumulation rate.

The agreement of our results with those of Boutron and Patterson (1983) suggests that the above constraints may not be too serious. It appears to confirm that the present-day mean $\mathrm{Pb}$ concentration in the Antarctic is about $6 \mathrm{pg} \mathrm{g}^{-1}$.

Boutron and Patterson (1983) and $\mathrm{Ng}$ and Patterson (1981) have shown that the upper limit for $\mathrm{Pb}$ in ancient Antarctic ice is not more than $1.2 \mathrm{pg} \mathrm{g}^{-1}$. Although it may appear that there has been at least a five-fold increase in $\mathrm{Pb}$ concentration in Antarctic ice over the last several thousand years, Boutron and Patterson (1983) found values as high as 3 to $4 \mathrm{pg} \mathrm{g}^{-1}$ in samples from the nineteenth century. This higher concentration may be due to an unexplained natural source (Boutron personal communication), hence any change due to anthropogenic emissions could be very small. However, we believe, as explained later and shown in Figure 5(c), that the $\mathrm{Pb}$ concentration for ancient ice given by Boutron and Patterson (1983) was dominated by contamination which has reached the centre of the blue-ice block; $\mathrm{Ng}$ and Patterson (1981) themselves stated that their value for ancient ice was an upper limit. Therefore the true $\mathrm{Pb}$ concentration is unknown. For ancient Greenland ice the observed upper limit of concentration for $\mathrm{Pb}\left(1.4 \mathrm{pg} \mathrm{g}^{-1}\right)$ reported by $\mathrm{Ng}$ and Patterson (1981) is consistent with an EF of approximately 1 . If we assume that the natural crustal enrichment factor for $\mathrm{Pb}$ in ancient Antarctic also approximates 1 and that the $\mathrm{Al}$ concentration is $1 \mathrm{ng} \mathrm{g}^{-1}$ (which may be an overestimate for some sites) we can place a lower limit of $0.15 \mathrm{pg} \mathrm{g}^{-1}$ on the $\mathrm{Pb}$ concentration in ancient ice. Thus the anthropogenic increase probably lies in the range 1 to 40 times the natural background level.

This result contrasts with the situation in Arctic areas, where several authors (Murozumi and others 1969, Herron and others 1977, Boutron 1979, Davidson and others 1981, Mart 1983) have shown that the concentration in modern snow is around $200 \mathrm{pg} \mathrm{g}^{-1}$. This concentration, which is so much higher than that in the Antarctic, undoubtedly reflects the much greater anthropogenic emissions in the northern hemisphere (Robinson and Robbins 1971) and the greater proximity of study areas to source areas in the north. Mart (1983) has shown that $\mathrm{Pb}$ concentrations in snow from the Arctic Ocean show a late summer minimum of $13 \mathrm{pg} \mathrm{g}^{-1}$. $\mathrm{He}$ believed that this value (and his minima for other elements) must be higher than those which would be found in modern snow from the much cleaner Antarctic, and so it has proved.

TABLE IV. ENRICHMENT FACTORS (EF) FOR SURFACE SAMPLES FROM SOUTHERN PALMER LAND PLATEAU

\begin{tabular}{|c|c|c|c|c|c|c|}
\hline SITE & SAMPLE & $\begin{array}{c}\text { Al } \\
\text { concentration } \\
\left(\mathrm{ng} \mathrm{\textrm {g } ^ { - 1 } )}\right.\end{array}$ & EF Cd & $\mathrm{EF} \mathrm{Cu}$ & $\mathrm{EF} \mathrm{Pb}$ & $\mathrm{EF} \mathrm{Zn}$ \\
\hline 1 & 7 & 0.85 & 140 & 4.0 & 36 & 7.2 \\
\hline 1 & 7 & 1.2 & - & - & - & - \\
\hline 1 & 7 & 0.9 & - & 1.8 & 95 & 4.7 \\
\hline 1 & 8 & 1.2 & 55 & 2.7 & 37 & 1.0 \\
\hline 1 & 9 & 1.0 & 70 & 3.0 & 20 & 8.7 \\
\hline 1 & 9 & 1.0 & 115 & 3.1 & - & 4.0 \\
\hline 2 & 1 & 0.5 & 280 & 6.9 & 43 & 7.3 \\
\hline 2 & 2 & 0.6 & 206 & 2.7 & 108 & 3.7 \\
\hline 2 & 2 & 0.7 & 182 & 3.0 & 92 & 1.7 \\
\hline 2 & 3 & 0.5 & 337 & 6.6 & 70 & 8.2 \\
\hline 3 & 4 & 0.4 & 226 & 6.7 & 99 & 8.2 \\
\hline 3 & 5 & 0.3 & 288 & 6.5 & 116 & 12.1 \\
\hline 3 & 5 & 0.5 & 99 & 7.5 & 34 & 8.2 \\
\hline \multicolumn{2}{|c|}{ All samples } & 0.7 & 182 & 4.5 & 68 & 6.3 \\
\hline \multicolumn{2}{|c|}{ Mean $\pm \begin{array}{c}\text { standard } \\
\text { deviation }\end{array}$} & \pm 0.3 & \pm 94 & \pm 2.1 & \pm 35 & \pm 3.2 \\
\hline
\end{tabular}




\subsection{Other heavy metals}

Our mean concentrations for the other heavy metals in snow deposited on the southern Palmer Land plateau are Cd: $0.26 \pm 0.09 \mathrm{pg} \mathrm{g}^{-1}, \mathrm{Cu}: 1.9 \pm 0.5 \mathrm{pg} \mathrm{g}^{-1}$ and $\mathrm{Zn}: 3.3 \pm 1.7$ $\mathrm{pg} \mathrm{g}^{-1}$. These values are at least 10 times lower than any other values reported for modern Antarctic snow (Boutron and Lorius 1979, Boutron 1980, 1982, Landy and Peel 1981, Peel and Wolff 1982). For reasons we have already discussed, our data could be unrepresentative. However, these other data were supported neither by cross-core profiles nor by full procedural blanks. In most cases, they are associated with $\mathrm{Pb}$ data which are clearly contaminated.

Our concentrations are also lower (by about 1 order of magnitude) than values for ancient ice from a blue-ice block from East Antarctica reported by Boutron and others (1984). These values were supported by both procedural blanks and profiles, so it is important to discuss how such a discrepancy could arise. We suggest three major reasons.

(i) Our data may not be representative of either the whole year or a lower accumulation site such as that of Boutron and others (1984). However, we have indicated earlier, when discussing our $\mathrm{Pb}$ data, that these are unlikely to be major factors, and would certainly not result in an order of magnitude discrepancy. The fact that our $\mathrm{Pb}$ data agreed with average values from a low accumulation site supports our belief.

(ii) Our data may not be quantitative, as we analyze samples acidified to $\mathrm{pH} 3$, whereas Boutron and others (1984) perform an acid digestion step. However, several authors (Nguyen and others 1979, Nürnberg and others 1982, Rohbock 1982) have shown that analyses at $\mathrm{pH} 2$ to 3 probably give a near total measurement of $\mathrm{Cd}, \mathrm{Cu}, \mathrm{Pb}$ and $\mathrm{Zn}$. We expect that metals not bound in crustal material will be dissolved at these acidities. Our $\mathrm{Pb}$ data in any case agreed with those of Boutron and Patterson (1983) obtained at a lower $\mathrm{pH}$ (though still without a full digestion). Our $\mathrm{Zn}$ analyses by direct injections should certainly be close to quantitative. Finally, in earlier studies (Landy and Peel 1981), no difference was found between concentrations measured before and after hot acid digestion. However, as this study may have analyzed contamination mainly, its significance is uncertain. Only comparative analyses on samples whose true concentrations are well established can clarify this point.

(iii) The final reason for the discrepancy could be that one or other of the sets of profiles may not really show a plateau. A linear scale may not be entirely appropriate for demonstrating this feature. Penetration of contamination by diffusion should follow functions related to the statistical error function (erf $\mathrm{x}$ ), which is similar to but steeper than an exponential. Alternatively, if contamination is transferred to the sample from tools, etc, as a sample is progressively cleaned up by shaving a sequence of veneers from the surface (following Boutron and Patterson (1983) and Boutron and others (1984)), then the decay profile should be semi-exponential. In either case a $\log$ plot of concentration versus distance (or number of samples) across the core may be more appropriate for demonstrating that a plateau has been reached. $\mathrm{Zn}$ profiles from the current work are presented in this way in Figure 5(a). In samples collected from southern Palmer Land the profiles exhibit a clear plateau whereas those collected from Spaatz Island show definite evidence for penetration of contamination. In Figures 5(b) and (c) we have plotted the data of Boutron and others (1984) for $\mathrm{Cd}, \mathrm{Cu}$ and $\mathrm{Zn}$ on a logarithmic scale. Although a plateau may be observed for $\mathrm{Cu}$, it is clear that penetration is still taking place for $\mathrm{Cd}$ and $\mathrm{Zn}$ near the centres of the samples and that the central values do not represent true ancient ice concentrations. Similarly, the $\mathrm{Pb}$ data of Boutron and Patterson (1983) for the same Wisconsin ice block have no plateau. Hence we consider that the true value for $\mathrm{Pb}$ in ancient ice may be much lower than so far reported. We conclude that there are no reliable data for the concentrations of $\mathrm{Cd}, \mathrm{Cu}$ and $\mathrm{Zn}$ in ancient ice. Our average EFs of $\mathrm{Cd}(182), \mathrm{Cu}(4.5)$ and $\mathrm{Zn}$ (6.3) can however be given as upper limits for increases due to anthropogenic emissions.

In comparison with Greenland and other Arctic data, our concentrations for modern snow are a factor of 19 times for $\mathrm{Cd}, 51$ times for $\mathrm{Cu}$ and 61 times for $\mathrm{Zn}$ lower

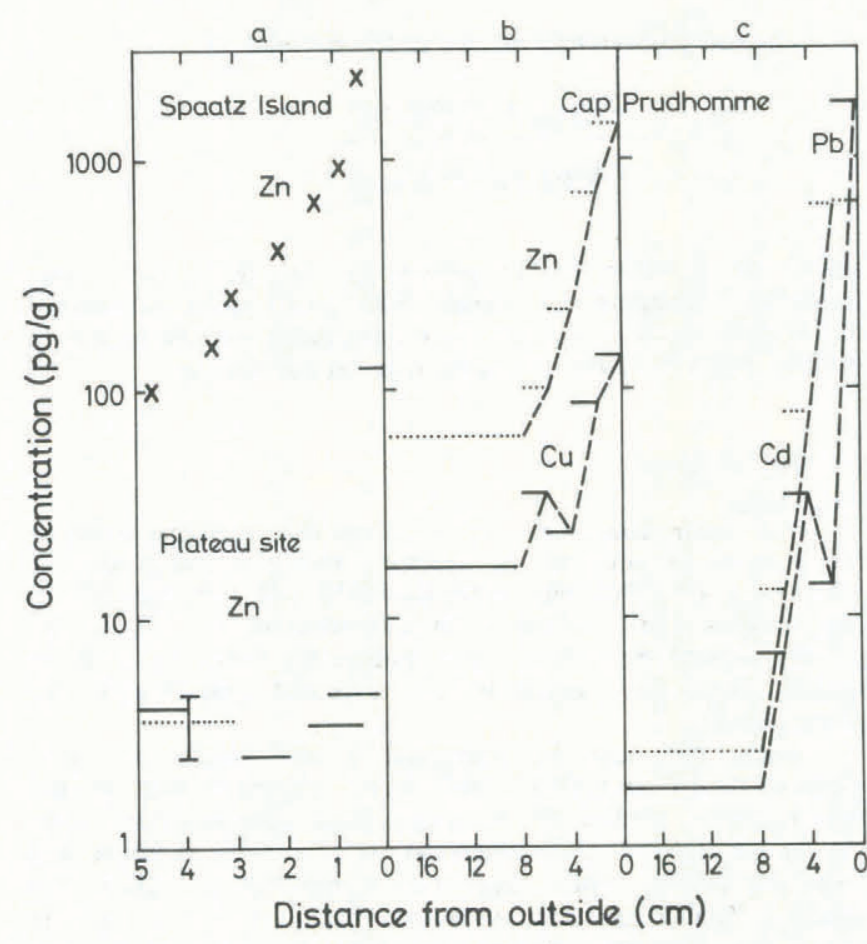

Fig.5. Profiles plotted on a logarithmic scale for (a) $\mathrm{Zn}$ in composite averaged values from seven cores at Spaatz Island (crosses); $\mathrm{Zn}$ in tube 3 , from southern Palmer Land plateau (bars). The dotted line is the average value from the large sub-sampler, with standard deviation of procedural blank as a vertical line. (b) and (c) $\mathrm{Cd}, \mathrm{Cu}$ and $\mathrm{Zn}$ from a blue-ice block $(10$ ka BP $)$ from Cap Prudhomme, a coastal area of East Antarctica (Boutron and others 1984), and $\mathrm{Pb}$ from the same block (Boutron and Patterson 1983)

than the most reliable average values reported for these areas (Herron and others 1977, Mart 1983). This reflects the much greater emissions and proximity to source areas in the northern hemisphere. On the basis of his later summer minimum concentrations in the Arctic, Mart (1983) suggested modern Antarctic snow should contain $\mathrm{Cd}<0.4 \mathrm{pg}$ $\mathrm{g}^{-1}$ and $\mathrm{Cu}<13 \mathrm{pg} \mathrm{g}^{-1}$. Our values support this suggestion.

\subsection{Enrichment factors (EF)}

Large EFs have been reported for a wide range of trace metals in both polar and oceanic regimes. As contamination control has improved, so the reported EFs or concentrations of the heavy metals have slowly reduced (Schaule and Patterson 1981, Bruland 1980, Boutron and Patterson 1983). Table IV now shows EFs in modern snow of 4.5 for $\mathrm{Cu}$ and 6.3 for $\mathrm{Zn}$. Since these ratios are similar to the ratios of present-day anthropogenic emission rates to estimates of natural airborne emission rates (Nriagu 1979), this suggests that ancient ice may not be significantly enriched in these elements. The $E F$ for $\mathrm{Pb}$ in ancient Antarctic ice can be estimated as approximately 10 from Boutron and Patterson (1983), but this value is probably still dominated by contamination. The average $\mathrm{EF}$ of 68 for $\mathrm{Pb}$ reported by us for modern Antarctic snow could be mainly anthropogenic in origin. These values suggest that high EFs reported from other remote areas may be subject to contamination. Other data presented here (Dick and Peel 1985) also demonstrate low EFs for heavy metals in the Antarctic aerosol.

A high EF of 182 is found only for Cd. As a volatile element, enrichment mechanisms such as volcanism (Boutron 1980) might appear attractive for $\mathrm{Cd}$. On the other hand, because the crustal abundance of $\mathrm{Cd}$ is very low, a comparatively small anthropogenic input (of order 20 times less than that we believe may exist for $\mathrm{Pb}$ ) could give rise to the observed EF.

Although we have shown that the EFs we observe may be anthropogenic in origin, this is based on data from a 
few samples of modern snow. Until reliable time series are established for these elements, extending back to ancient times, we cannot rule out the possibility that there has been no significant anthropogenic increase.

\section{FUTURE WORK}

Our study has shown that both proper procedural blank control and supporting concentration profiles across representative samples are essential for heavy metal measurements in polar snow. For the lower concentrations expected in ancient ice, still further improvements in contamination control and sensitivity of analytical techniques will be needed.

The type of sample collected is also important. Cores may be adequate provided the analytical technique requires sufficiently small samples, although large blocks would make detailed profiling easier. Good temperature control of collected samples is crucial to avoid excessive penetration of contaminants.

In the case of our own work, it is important that we show unequivocally how quantitative our data are. Comparative studies using an independent analytical approach would be ideal if similar blank control can be attained.

Finally, having established that heavy metal concentrations in Antarctic snow lie at an unprecedently low level, the studies must be extended to time-series samples in order that we can trace finally and correctly both the short-term variability and the long-term trends of heavy metal concentrations in Antarctic ice.

\section{REFERENCES}

Boutron C 1979 Trace element content of Greenland snows along an east-west transect. Geochimica et Cosmochimica Acta 43(8): 1253-1258

Boutron C 1980 Respective influence of global pollution and volcanic eruptions on the past variations of the trace metals content of Antarctic snows since 1880s. Journal of Geophysical Research 85(C12): 7426-7432

Boutron C 1982 Atmospheric trace metals in the snow layers deposited at the South Pole from 1928 to 1977. Atmospheric Environment 16(10): 2451-2459

Boutron C, Lorius C 1979 Trace metals in Antarctic snows since 1914. Nature 277(5679): 551-554

Boutron C F, Patterson C C 1983 The occurrence of lead in Antarctic recent snow, firn deposited over the last two centuries and prehistoric ice. Geochimica et Cosmochimica Acta 47: 1355-1368

Boutron C, Leclerc M, Risler N 1984 Atmospheric trace elements in Antarctic prehistoric ice collected at a coastal ablation area. Atmospheric Environment 18(9): 1947-1954

Bruland K W 1980 Oceanographic distribution of cadmium, zinc, nickel and copper in the North Pacific. Earth and Planetary Science Letters 47: 176-198

Davidson C I, Chu L, Grimm T C, Nasta M A, Qamoos M P 1981 Wet and dry deposition of trace elements onto the Greenland ice sheet. Atmospheric Environment 15(8): 1429-1437

Dick A L, Peel D A 1985 Trace elements in Antarctic air and snowfall. Annals of Glaciology 7: 12-19

Herron M M, Langway C C Jr, Weiss $\mathrm{H} \mathrm{V}$, Cragin $\mathrm{J} \mathrm{H}$ 1977 Atmospheric trace metals and sulfate in the Greenland ice sheet. Geochimica et Cosmochimica Acta 41(7): $915-920$

Junge C E 1977 Processes responsible for the trace content in precipitation. International Association of Hydrological Sciences Publication 118 (General Assembly of Grenoble 1975 - Isotopes and Impurities in Snow and Ice): 63-77

Landy M P, Peel D A 1981 Short-term fluctuations in heavy metal concentrations in Antarctic snow. Nature 291(5811): 144-146

Langway C C Jr, Klouda G A, Herron M M, Cragin $\mathbf{J} H$ 1977 Seasonal variations of chemical constituents in annual layers of Greenland deep ice deposits. International Association of Hydrological Sciences Publication 118 (General Assembly of Grenoble 1975 - Isotopes and Impurities in Snow and Ice): 302--306
Mart L 1983 Seasonal variations of $\mathrm{Cd}, \mathrm{Pb}, \mathrm{Cu}$ and $\mathrm{Ni}$ levels in snow from the eastern Arctic Ocean. Tellus 35B(2): 131-141

Moody J R, Lindstrom R M 1977 Selection and cleaning of plastic containers for storage of trace element samples. Analytical Chemistry 49(14): 2264-2267

Murozumi M, Chow T J, Patterson C C 1969 Chemical concentrations of pollutant lead aerosols, terrestrial dusts and sea salts in Greenland and Antarctic snow strata. Geochimica et Cosmochimica Acta 33(10): 1247-1294

$\mathrm{Ng} \mathrm{A}$, Patterson C C 1981 Natural concentrations of lead in ancient Arctic and Antarctic ice. Geochimica et Cosmochimica Acta 45(11): 2109-2121

Nguyen V D, Valenta P, Nürnberg H W 1979 The determination of toxic trace metals in rainwater and snow by differential pulse stripping voltammetry. Science of the Total Environment 12: 151-167

Nriagu J O 1979 Global inventory of natural and anthropegenic emissions of trace metals to the atmosphere. Nature 279(5712): 409-411

Nürnberg H W, Valenta P, Nguyen V D 1982 Wet deposition of toxic metals from the atmosphere in the Federal Republic of Germany. In Georgii H-W, Pankrath $\mathrm{J}$ (eds) Deposition of atmospheric pollutants. Dordrecht, D Reidel: $143-157$

Peel D A, Wolff E W 1982 Recent variations in heavy metal concentrations in firn and air from the Antarctic Peninsula. Annals of Glaciology 3: 255-259

Robinson E, Robbins R C 1971 Emissions, concentrations and fate of particulate atmospheric pollutants. Washington, DC, American Petroleum Institute (Publication 4070)

Rohbock E 1982 Atmospheric removal of airborne metals by wet and dry deposition. In Georgii $\mathrm{H}-\mathrm{W}$, Pankrath J (eds) Deposition of atmospheric pollutants. Dordrecht, D Reidel: $159-171$

Schaule B K, Patterson C C 1981 Lead concentrations in the northeast Pacific: evidence for global anthropogenic perturbations. Earth and Planetary Science Letters 54: 97-116

Shaw G E 1980 Optical, chemical and physical properties of aerosols over the Antarctic ice sheet. Atmospheric Environment 14(8): 911-921

Wolff E W, Landy M P, Peel D A 1981 Preconcentration of cadmium, copper, lead and zinc in water at the $10^{-12}$ $\mathrm{g} / \mathrm{g}$ level by adsorption onto tungsten wire followed by flameless atomic spectrometry. Analytical Chemistry 53(11): 1566-1570

Wolff E W, Peel D A 1985 The record of global pollution in polar snow and ice. Nature 313(6003): 535-540 